Special issue of the 3rd International Conference on Computational and Experimental Science and Engineering (ICCESEN 2016)

\title{
Mechanical and Tribological Behaviour of Chopped E-Glass Fiber-Reinforced Epoxy Composite Materials
}

\author{
N. Ozsoy*, M. Ozsoy and A. Mimaroglu \\ Sakarya University, Faculty of Engineering, Mechanical Engineering Department, Serdivan, Sakarya, Turkey \\ Chopped E-glass fiber-reinforced epoxy composites (10\%, 30\% and 50\%) were fabricated and their mechanical \\ and tribological behaviour was investigated. Three-point bending tests were performed according to the ASTMD790 \\ and tensile tests were performed according to the ASTMD638 standards. Impact tests and hardness measurements \\ of the composites were also carried out. Wear behaviour of composites was studied using pin on disc wear testing \\ device. The design of experiments approach, using Taguchi method, was employed to analyze the results. Signal- \\ to-noise ratio and analysis of variance were used to determine the influence of parameters on the wear rate and \\ coefficient of friction.
}

DOI: 10.12693/APhysPolA.132.852

PACS/topics: 81.05.Qk, 07.05.Fb, 62.20.Qp, 81.70.Bt

\section{Introduction}

A composite material can be defined as a combination of two or more materials that results in better properties than those of the individual components, used alone. In contrast to metallic alloys, each material retains its separate chemical, physical, and mechanical properties. The two constituents are reinforcement and matrix. The main advantages of composite materials are their high strength and stiffness, combined with low density, when compared with bulk materials, allowing for a weight reduction in the finished part [1].

In general, fibers are the principal load bearing members, while the matrix places them at the desired location and orientation, and acts as a load-transfer medium between them, and protects them from environmental damage [2]. Eksi and Genel investigated experimentally bending behavior of hybrid composites, reinforced by different types of fibers. In the preparation of composite samples, different number of layers was used, having the same thickness. Woven glass, aramid and carbon fibers were used in the composites. Three-point bending test was carried out to determine bending behavior of the samples. Authors have shown that regardless of fiber type, the load bearing capacity and energy absorption capability are increased by increasing the number of layers [3].

Experimental investigation of tribological properties requires a lot of time, and thus is difficult to perform. Taguchi method is used to simplify such procedures. Many researchers have used this method $[2,4-6]$. Design of experiment is one of the important and powerful statistical techniques to study the effect of multiple variables simultaneously, which involves a series of steps, which must follow a certain sequence for the experiment to yield

*corresponding author; e-mail: nerken@sakarya.edu.tr an improved understanding of process performance [7]. Wear problems are very important in industry, especially in elements of machines [8].

Many researchers have studied epoxy composites. Suresha et al. investigated three-body abrasive wear behaviour of carbon-epoxy and glass-epoxy composites. They have studied the effect of abrading distance, viz., 270, 540,810 and $1080 \mathrm{~m}$ and of different loads of 22 and $32 \mathrm{~N}$ at $200 \mathrm{rpm}$. The study showed that wear volume loss increases with increasing load/abrading distance [9].

Pihtılı examined the effects of resin content on the wear of woven roving glass fibre-epoxy resin and glass fibre-polyester resin composite materials [10]. Nasir et al. studied adhesion and friction of E-glass fiber-reinforced epoxy (E-GFRE) composites. They found that the wear resistance of E-GFRE composites can be improved by inserting approximately 5-10 wt.\% of C-filler loading. Above 10 wt.\%, the wear mass loss increased linearly with increasing C-filler loading. The reinforced C-filled E-GFRE composites have almost the same friction coefficient as the pure epoxy matrix, which increased slightly with the increasing C-filler loading [11]. Yilmazcoban and Doner carried out the ballistic protection evaluation of sequenced composite material sandwich panels for the reliable combination of armor layers [12].

In the present work it is aimed to investigate mechanical and tribological properties of CFRE composites. It is also aimed to plan wear experiments by Taguchi method and to analyze the results with ANOVA.

\section{Tribological experiments}

In this study the materials used for composite preparing were chopped E-glass fiber, used as reinforcement, and the epoxy, used as matrix material. Two different moulds were manufactured for sample preparation for tribological and mechanical studies.

Epoxy resin (MGS L285) was mixed with hardener (HGS L285) in mass ratio of $100 / 40$, as recommended 
by the supplier and then chopped E-glass fiber was added to the matrix in quantity of 10, 30 and 50 wt.\%. The fiber and epoxy mixture was poured in the mould and heated to $60^{\circ} \mathrm{C}$ for one hour in an oven, and after that cured at room temperature for 24 hours, to make test samples for wearing test. In the mould the wearing pin samples had a diameter of $10 \mathrm{~mm}$. After curing they were machined to $6 \mathrm{~mm}$, for the tests.

A pin on disc wear testing machine was used to investigate the dry sliding wear characteristics of composites, according to ASTM G99-95 [13] standards. The wear specimen (pin) was $6 \mathrm{~mm}$ in diameter and $30 \mathrm{~mm}$ in height. The initial weight of the specimen was measured using an electronic balance machine with accuracy of $0.0001 \mathrm{~g}$. During the test, the pin was pressed against the counter part EN19 steel disc with hardness of $60 \mathrm{HRC}$, by applying the load. After running through a fixed sliding distance of $1000 \mathrm{~m}$, the specimens were removed, cleaned with acetone, dried and weighted to determine the weight loss due to wear. The difference in the weight, measured before and after the test gave the sliding wear of the composite specimen. The density of the specimens was measured and then the sliding wear of the composite was calculated according to Eq. (1), where $\Delta m$ is difference in mass, $\rho$ is density and $d$ is the sliding distance.

Wear rate $=\frac{\Delta m}{\rho d}$.

\subsection{Plan of experiments}

Dry sliding wear tests were performed with three varied parameters: applied load $(20,30,40 \mathrm{~N})$, sliding speed
$(0.6,0.8,1 \mathrm{~m} / \mathrm{s})$ and weight $\%$ fraction of the fiber $(10,30$, $50)$. According to the rule that degree of freedom for an orthogonal array should be greater than or equal to sum of those wear parameters, the L9 orthogonal array, which has 9 rows and 3 columns, was selected. The response variables to be studied were wear rate and coefficient of friction.

The experiments were conducted based on the run order, generated by Taguchi model and the results were obtained. The analyses of experimental data were carried out using MINITAB 15 software, which is specially used for design of experiment applications. The experimental results were transformed into signal to noise $(\mathrm{S} / \mathrm{N})$ ratios. $\mathrm{S} / \mathrm{N}$ ratio is defined as the ratio of the mean of the signal to the standard deviation of the noise. The $\mathrm{S} / \mathrm{N}$ ratio indicates the degree of the predictable performance of a product or process in the presence of noise factors. Process parameter settings with the highest $\mathrm{S} / \mathrm{N}$ ratio always yield the optimum quality with minimum variance. The $\mathrm{S} / \mathrm{N}$ ratio for wear rate and coefficient of friction, using "smaller the better" characteristic, which can be calculated as logarithmic transformation of the loss function, is given as:

$$
\mathrm{S} / \mathrm{N}=-10 \log \left[\frac{1}{n \sum y^{2}}\right],
$$

where $y$ is the observed data (wear rate or coefficient of friction) and $n$ is the number of observations.

\subsection{Experimental results}

Results of L9 orthogonal array for chopped E-glass fiber-reinforced epoxy composites are given in Table I.

TABLE I

Results of L9 orthogonal array for chopped E-glass fiber reinforced epoxy composites.

\begin{tabular}{c|c|c|c|c|c|c|c}
\hline \hline $\begin{array}{c}\text { Experiment } \\
\text { number }\end{array}$ & $\begin{array}{c}\text { Load } \\
{[\mathrm{N}]}\end{array}$ & $\begin{array}{c}\text { Sliding } \\
\text { speed } \\
{[\mathrm{m} / \mathrm{s}]}\end{array}$ & $\begin{array}{c}\text { Wt. pct } \\
{[\%]}\end{array}$ & $\begin{array}{c}\text { Wear rate } \\
{\left[\mathrm{mm}^{3} / \mathrm{m}\right]}\end{array}$ & $\begin{array}{c}\text { Coefficient } \\
\text { of } \\
\text { friction }\end{array}$ & $\begin{array}{c}\text { S/N ratio } \\
\text { of wear rate } \\
{[\mathrm{dB}]}\end{array}$ & $\begin{array}{c}\text { S/N ratio } \\
\text { of coefficient } \\
\text { of friction } \\
{[\mathrm{dB}]}\end{array}$ \\
\hline 1 & 20 & 0.6 & 10 & 0.00063 & 0.560 & 52.563 & 5.020 \\
2 & 20 & 0.8 & 30 & 0.00144 & 0.656 & 56.785 & 3.655 \\
3 & 20 & 1 & 50 & 0.00136 & 0.653 & 57.301 & 3.689 \\
4 & 30 & 0.6 & 30 & 0.00213 & 0.690 & 51.479 & 3.214 \\
5 & 30 & 0.8 & 50 & 0.00416 & 0.746 & 47.615 & 2.537 \\
6 & 30 & 1 & 10 & 0.14494 & 0.809 & 19.764 & 1.834 \\
7 & 40 & 0.6 & 50 & 0.00457 & 0.705 & 28.803 & 3.024 \\
8 & 40 & 0.8 & 10 & 0.11333 & 0.832 & 18.912 & 1.593 \\
9 & 40 & 1 & 30 & 0.08777 & 0.848 & 18.306 & 1.425
\end{tabular}

It can be observed from Table I, that optimum conditions for wear rate has the 3rd experiment and for the coefficient of friction it is the 1st experiment. In these experiments the biggest $\mathrm{S} / \mathrm{N}$ ratios were obtained.
The control parameter with the strongest influence was determined by the difference between the maximum and minimum value of the mean of $\mathrm{S} / \mathrm{N}$ ratios. Higher the difference between the mean of $\mathrm{S} / \mathrm{N}$ ratios, the more influ- 
TABLE II

Response table for $\mathrm{S} / \mathrm{N}$ ratio for wear rate.

\begin{tabular}{c|c|c|c}
\hline \hline Level & Load & $\begin{array}{c}\text { Sliding speed } \\
{[\mathrm{m} / \mathrm{s}]}\end{array}$ & Wt. pct [\%] \\
\hline 1 & 55.55 & 44.28 & 30.41 \\
2 & 39.62 & 41,10 & 42.19 \\
3 & 22.01 & 31.79 & 44.57 \\
Delta & 33.54 & 12.49 & 14.16 \\
Rank & 1 & 3 & 2
\end{tabular}

TABLE III

Response table for $\mathrm{S} / \mathrm{N}$ ratio for coefficient of friction.

\begin{tabular}{c|c|c|c}
\hline \hline Level & Load & $\begin{array}{c}\text { Sliding speed } \\
{[\mathrm{m} / \mathrm{s}]}\end{array}$ & Wt. pct [\%] \\
\hline 1 & 4.122 & 3.753 & 2.816 \\
2 & 2.529 & 2.595 & 2.765 \\
3 & 2.015 & 2.317 & 3.084 \\
Delta & 2.107 & 1.437 & 0.319 \\
Rank & 1 & 2 & 3
\end{tabular}

ential was the control parameter. From Tables II and III it can be observed, that load is the dominant parameter for the wear rate and coefficient of friction. Load is generally the dominant parameter of the wear rate [14]. Weight percentage of chopped E-glass fiber is the second parameter that influences the wear rate. Sliding speed is the second effective parameter for the coefficient of friction.

\subsubsection{Analysis of variance}

Analysis of variance (ANOVA) is used to analyze the influence of wear parameters, like sliding speed, applied load and weight percentage of fibers on the tribological performance characteristics: wear and coefficient of friction. These analyses were carried out for the level of significance of $10 \%$ with $90 \%$ confidential level. If $F$ is high, the contribution of the factors to that particular response is high [15]. Tables IV and V show the results of ANOVA analysis for wear rate and coefficient of friction. The value of total sum of squares is used to measure the relative influence of the factors. The larger the value of sum of squares, the more influential the factor is for controlling the responses. These values are used to determine the percentage contribution factors. From Table IV, it is found that load $(52.11 \%)$ is the most significant factor on wear rate, second factor is sliding speed $(24.8 \%)$ and third factor is weight percentage of glass fiber $(22.64 \%)$.

TABLE IV

ANOVA for wear rate.

\begin{tabular}{c|c|c|c|c|c|c}
\hline \hline Source & DOF & Seq. SS & Adj. SS & Adj. MS & F & $\begin{array}{c}\% \\
\text { contribution }\end{array}$ \\
\hline Load & 2 & 0.0119728 & 0.0119728 & 0.0059864 & 134.13 & 52.11 \\
Sliding speed & 2 & 0.0057093 & 0.0057093 & 0.0028547 & 63.96 & 24.8 \\
Wt. pct(\%) & 2 & 0.0052034 & 0.0052034 & 0.0026017 & 58.29 & 22.64 \\
Error & 2 & 0.0000893 & 0.0000893 & 0.0000446 & & 0.45 \\
Total & 8 & 0.0229748 & & & & \\
\hline
\end{tabular}

DOF: Degree of freedom; Seq. SS: Sequential sum of squares; Adj. SS: Adjusted sum of squares; Adj. MS: Adjusted mean squares.

TABLE V

ANOVA for coefficient of friction.

\begin{tabular}{c|c|c|c|c|c|c}
\hline \hline Source & DOF & Seq. SS & Adj. SS & Adj. MS & F & $\begin{array}{c}\% \\
\text { contribution }\end{array}$ \\
\hline Load & 2 & 0.04738 & 0.047389 & 0.023695 & 607.23 & 65.27 \\
Sliding speed & 2 & 0.023204 & 0.023204 & 0.011602 & 297.33 & 31.96 \\
Wt. pct(\%) & 2 & 0.001928 & 0.001928 & 0.000964 & 24.71 & 2.65 \\
Error & 2 & 0.000078 & 0.000078 & 0.000039 & & 0.12 \\
Total & 8 & 0.072599 & & & & \\
\hline
\end{tabular}

On the other hand, according to the analysis of variance for coefficient of friction from Table V, applied load $(65.27 \%)$ is the most significant factor, followed by sliding speed and weight percentage of glass fiber. The influence of weight percentage can be neglected.

\subsubsection{Confirmation tests}

The last step for Taguchi analysis is the confirmation test. According to Taguchi analyses, optimum levels of parameters were determined according to Tables II 
and III. The confirmation experiments were performed by taking an arbitrary set of factor combination $\mathrm{A}_{1} \mathrm{~B}_{1} \mathrm{C}_{3}$ for wear rate and $\mathrm{A}_{1} \mathrm{~B}_{1} \mathrm{C}_{3}$ for coefficient of friction. The estimated $\mathrm{S} / \mathrm{N}$ ratio can be calculated according to Eq. (3) for wear rate and Eq. (4) for coefficient of friction.

$$
\begin{aligned}
& \hat{\eta}=\bar{T}+\left(\overline{A_{1}}-\bar{T}\right)+\left(\bar{B}_{1}-\bar{T}\right)+\left(\bar{C}_{3}-\bar{T}\right), \\
& \hat{\eta}=\bar{T}+\left(\overline{A_{1}}-\bar{T}\right)+\left(\bar{B}_{1}-\bar{T}\right)+\left(\bar{C}_{3}-\bar{T}\right) .
\end{aligned}
$$

\section{TABLE VI}

Confirmation tests results.

\begin{tabular}{c|c|c}
\hline \hline \multicolumn{3}{c}{ Level: $\mathrm{A}_{1} \mathrm{~B}_{1} \mathrm{C}_{3}$} \\
\hline \multicolumn{3}{c}{$\mathrm{S} / \mathrm{N}$ ratio of wear rate $[\mathrm{dB}]$} \\
\hline Predicted & Experimental & $\%$ Error \\
\hline 66.287 & 64.584 & 2.637 \\
\hline $\mathrm{S} / \mathrm{N}$ ratio of coefficient of friction $[\mathrm{dB}]$ \\
\hline 5.182 & 5.516 & 6.049
\end{tabular}

Table VI shows the comparison of the predicted wear rate and frictional force with the actual response under study. The error is calculated between actual and predicted values of $\mathrm{S} / \mathrm{N}$ ratio. The predicted error for wear rate is $2.637 \%$ and for coefficient of friction it is $6.049 \%$. This verifies that the predicted values are reliable.

\subsection{Surface morphology}

SEM examinations of worn surfaces were made to investigate the wear mechanisms, as shown in Fig. 1. The rupture of the pin, caused by the high velocity and the low percentage of the reinforcement, can be seen in Fig. 1a. For the amount of the reinforcement of $30 \mathrm{wt} . \%$, the hardness increased and a smoother surface can be seen in Fig. 1b. On the other hand, here there are voids, which occurred during the manufacturing process. In Fig. 1c, wear tracks can be seen in the sliding direction. In this study the general wear mechanism was the abrasive wear.

Values of the coefficient of friction were high, because of weak bonding of matrix and reinforcement. During the tribological tests, particles of pin, ruptured from the surface, have caused an abrasive effect.

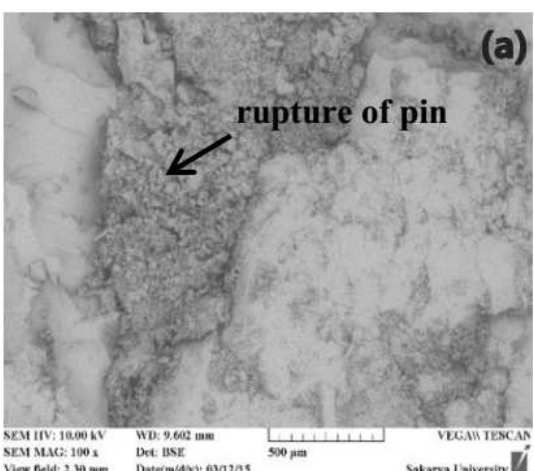

Fig. 1. SEM images of worn surfaces reinforced, $30 \mathrm{~N}, 0.8 \mathrm{~m} / \mathrm{s}$.

\section{Mechanical tests}

A special mold was manufactured to prepare the mechanical test specimens. Before the mixture was placed inside the mold, the mold was polished with a release agent to prevent the composites from sticking to the mold, upon removal of mechanical test samples. Mixture was poured into the mold. The mold was closed under press to avoid occurrence of air bubbles in the composites and heated to $60^{\circ} \mathrm{C}$ for one hour. After that, composites were cured in the mold for 24 hours at room conditions. When the composite was hardened, it was removed from the mold.

Tension samples were prepared according to ASTM D638 [16]. Tensile tests were conducted with Zwick Roell device at room conditions. Test speed was $2 \mathrm{~mm} / \mathrm{min}$. Bending samples were prepared according to the ASTM D790 (2010) [17] and the dimensions of the samples were $12.7 \times 127 \times 3.2 \mathrm{~mm}^{3}$. Three-point bending tests were stopped automatically, when the plastic deformation started in the composite.
Impact tests were conducted according to ASTM D4812-11 [18] with the samples, which had the dimensions of $12.7 \times 63.5 \times 3.2 \mathrm{~mm}^{3}$ and during the tests samples were positioned vertically according to Izod. The impact tests were performed under a hammer, which had $5.5 \mathrm{~J}$ of energy.

Hardness of the samples was measured with a Barcol measurement device according to ASTM D2583 [19]. All mechanical tests were repeated on five samples and the average values were considered. The tests were conducted at room conditions.

Results of tensile test are shown in Table VII. The results show that reinforcement of chopped glass fiber was not effective for increasing the tensile strength. The epoxy, used as the matrix material, had tensile strength of $73.5 \mathrm{MPa} .30 \mathrm{wt} . \%$ reinforced composites had the highest tensile strength, with the value of $51 \mathrm{MPa}$. As the fiber content exceed $30 \%$, the tensile strength started to decrease. Because matrix material was not able to hold the fibers together, the optimum value was exceeded. 
Results of bending test are shown in Table VII. Bending stress was $105 \mathrm{MPa}, 92.25 \mathrm{MPa}, 113 \mathrm{MPa}$ and $93 \mathrm{MPa}$ in pure epoxy, 10 wt.\%, 30 wt.\% and 50 wt.\% reinforced composites, respectively. According to the results it can be said that chopped glass fiber reinforcement had not increased the bending strength.

Results of impact test are shown in Table VII. It can be seen that the impact energy was $314.313 \mathrm{~J} / \mathrm{m}$ in pure epoxy, $107.062 \mathrm{~J} / \mathrm{m}$ in $10 \mathrm{wt} \%$ reinforced composites, with a $38 \%$ increase, $435.073 \mathrm{~J} / \mathrm{m}$ in 30 wt.\% reinforced composites, with a $90 \%$ increase and $597.390 \mathrm{~J} / \mathrm{m}$ in 50 wt.\% reinforced composites. As the amount of reinforcement reached $30 \mathrm{wt} . \%$, the impact energy started to increase.

Results of hardness test are shown in Table VII. As the amount of chopped glass fiber in the composite increased, the hardness increased too. The hardness was $2 \%$ higher with 10 wt.\% reinforcement, $11 \%$ higher with 30 wt.\% reinforcement and 34\% higher with 50 wt.\% reinforcement in the composite, compared to the pure matrix material.

TABLE VII

Mechanical test results.

\begin{tabular}{c|c|c|c|c}
\hline \hline & $\begin{array}{c}\text { Pure } \\
\text { epoxy }\end{array}$ & 10 wt.\% & 30 wt.\% & 50 wt.\% \\
\hline Tensile strength [MPa] & 73.5 & 42 & 51 & 43 \\
Bending strength [MPa] & 105 & 92.25 & 113 & 93 \\
Impact energy [J/m] & 314.3 & 107.1 & 435.1 & 597.4 \\
Barcol hardness & 33.2 & 34 & 37 & 44.6
\end{tabular}

According to the mechanical test results, it is seen that reinforcement of glass fiber did not generally improve the performance of the composites. There are some reasons that can affect the results. According to one of them, as fiber is chopped, its mechanical performance becomes not good, as that of the continuous fibers. On the other hand, voids have occurred during composite manufacturing and decreased the mechanical performance. Lastly, the matrix material has a capacity to hold fibers together. When this limit is exceeded, it cannot be successful as the binding medium and the interaction between the matrix and reinforcement becomes weak to external loads.

\section{Conclusions}

Dry sliding wear and coefficient of friction of the composite materials were successfully analysed using Taguchi design of experiment, under different loads and sliding speeds.

Applied load had the highest influence $(52.11 \%$ ) on the wear rate of glass fiber reinforced epoxy composites. According to the analysis of variance for coefficient of friction, the applied load was again the most significant factor $(65.27 \%)$.
The $\mathrm{S} / \mathrm{N}$ ratio, estimated using the optimal testing parameters, for wear rate and coefficient of friction were calculated and a good agreement between the predicted and actual wear rates and coefficients of friction were observed.

Tensile strength was decreased with the reinforcement. Furthermore, bending strength was not influenced. The impact strength and hardness values were better in composites than in the pure epoxy.

\section{References}

[1] F.C. Campbell, Structural composite materials, ASM International, 2010.

[2] Siddhartha, K. Gupta, Mater. Des. 35, 467 (2012).

[3] S. Eksi, K. Genel, Acta Phys. Pol. A 128, B-59 (2015).

[4] T.R. Hemanth Kumar, R.P. Swamyand, T.K. Chandrashekar, J. Miner. Mater. Charact. Engin. 10, 1179 (2011).

[5] S. Koksal, F. Ficici, R. Kayikci, O. Savas, Mater. Des. 42, 124 (2012).

[6] Y. Sahin, Tribol. Int. 43, 939 (2010).

[7] Y. Sahin, Mater. Sci. Engin. A 408, 1 (2005).

[8] M. Uzun, K. Yildiz, Acta Phys. Pol. A 128, B-337 (2015).

[9] B. Suresha, G. Chandramohan, Siddaramaiah, P. Samapthkumaran, S. Seetharamu, Mater. Sci. Engin. A 443, 285 (2007).

[10] H. Pıhtılı, Europ. Polymer J. 45, 149 (2009).

[11] R. MD. Nasir, M.M. Azizan, J. Thermoplastic Compos. Mater. 24, 861 (2011).

[12] K. Yilmazcoban, S. Doner, Acta Phys. Pol. A 130, 342 (2016).

[13] ASTM G99-95 Standard Test Method for Wear Testing with a Pin-on-Disk Apparatus.

[14] A. Gunen, Acta Phys. Pol. A 130, 217 (2016).

[15] E. Kanca, F. Cavdar, M.M. Ersen, Acta Phys. Pol. A 130, 365 (2016).

[16] ASTM D638M-96, Standard test method for tensile properties of plastics (metric), American Society for Testing and Material, 1996.

[17] ASTM D790-10, Standard test methods for flexural properties of unreinforced and reinforced plastics and electrical insulating materials, American Society for Testing and Material, 2010.

[18] ASTM D4812-11, Standard test method for unnotched cantilever beam impact resistance of plastics, American Society for Testing and Material, 2011.

[19] ASTM D-2583, Standard test method for indentation hardness of rigid plastics by means of a Barcol impressor, American Society for Testing and Material, 2013. 